\title{
AGLOSSIA CONGENITA
}

\author{
BY \\ G. M. ARDRAN, J. M. BECKETT, and F. H. KEMP \\ From the Nuffield Institute for Medical Research, University of Oxford, \\ and the Health Department, Nuneaton
}

(RECEIVED FOR PUBLICATION DECEMBER 31, 1963)

In a previous paper (Fulford, Ardran, and Kemp, 1956) we described the clinical findings of a child born with the anterior two-thirds of the tongue absent. Cineradiographic observations were made at 6 months and 10 months of age while the child was swallowing. A brief review was given of 12 other cases previously described. Pettersson (1961) described a child who had malformations of the hands in that the left thumb had no thumbnail, and the right thumbnail was poorly developed; the second digit on both hands had only two phalanges. Radiological examination showed normal mandibular joints but the upper and lower jaws were united by bony fusion anteriorly in the mid-line. This deformity was corrected by operation and the child was in good condition at the age of $2 \frac{1}{2}$ years and could speak single words: he could eat all kinds of food but preferred them mashed. His teeth were asymmetrical and he could only open his mouth about $1 \mathrm{~cm}$.

\section{Case Report}

Our patient is now 8 years and 6 months old: he has been examined several times and recently has had a new assessment of his swallowing and speech mechanisms. In view of the rarity of these cases it was thought to be of interest to submit the following brief report, though it is hoped to continue investigation into this child's speech.

Clinical Observations. He is a child of average health; he attends school and is making normal progress. The syndactyly previously described between the index and the middle fingers of the left hand has been corrected surgically. Previously this child used to tilt his head backwards to allow fluid to flow into his pharynx; he ceased to do this after the age of 16 months. Similarly, when first taking solid food, he frequently had to use his fingers to dislodge food from his hard palate, he now seldom needs to do this. He has no difficulty with breathing and does not dribble saliva. He appears to have good taste discrimination.

Cineradiographic Observations of Swallowing. Lateral cineradiography shows that when swallowing fluid barium suspension in the erect position at the age of $8 \frac{1}{2}$ he has no difficulty in ciearing the mouth of the main bulk of the contents in one swallow. The floor of the mouth and tongue rise towards the hard palate, leaving only a small pocket of barium on the floor of the mouth just behind the lower incisor teeth. Clearance from the remainder of the mouth is fairly good but more traces are left than with a normal child: a second swallow removes all but a minimum residue: since this child does not dribble it is obvious that he can clear this region of his mouth (Fig. 1). Antero-posterior examination shows that the bolus passes down the mid-line in the normal manner.

When sucking through a straw he can obtain a good mouthful of fluid which is swallowed with a similar residue to that just described. Whereas the normal subject holds the column of fluid in the straw by occluding its end with the tip of the tongue, ready for a further suck, this child occludes the open end of the tube with the rather redundant tissue of the lower lip, which he pushes into place in front of the lower incisor teeth (Fig. 2).

Speech Assessment. The general impression of the speech is that it appears slightly hyperrhinophonic in quality and some consonants are a little blurred, while one or two others are misarticulated. The speech is, however, readily intelligible and no communication difficulties have arisen. Ten untrained listeners on hearing a recording of his speech understood every word though several passed the comment that it sounded rather slurred.

Most consonants are acoustically acceptable; the consonant ' $s$ ' sounds somewhat lateral to the trained ear and on investigation the air proves to be released unilaterally to the left of the front incisors. The ' $r$ ' sound is acceptable, the 'th' $(\theta)$ sound is substituted by ' $f$ ' as would be expected and ' $y$ ' $(j)$ takes the place of ' $l$ '. It has recently been possible to elicit (by imitation) a sound that more nearly approaches an acoeptable 'l' sound. Phonetically the sound produced is ' $y$ ' (j).

Radiographic Observations of Speech. All the examinations of speech sounds are difficult to visualize clearly because the soft tissue outline of the floor of the mouth and tongue is obscured by the overlapping and erupting teeth.

Lateral Cineradiographic Films While Attempting ' $L e$ ' (l). It would appear this child tries to make this sound by flapping his tongue against his fauces and tonsils rather than with any action anteriorly. 

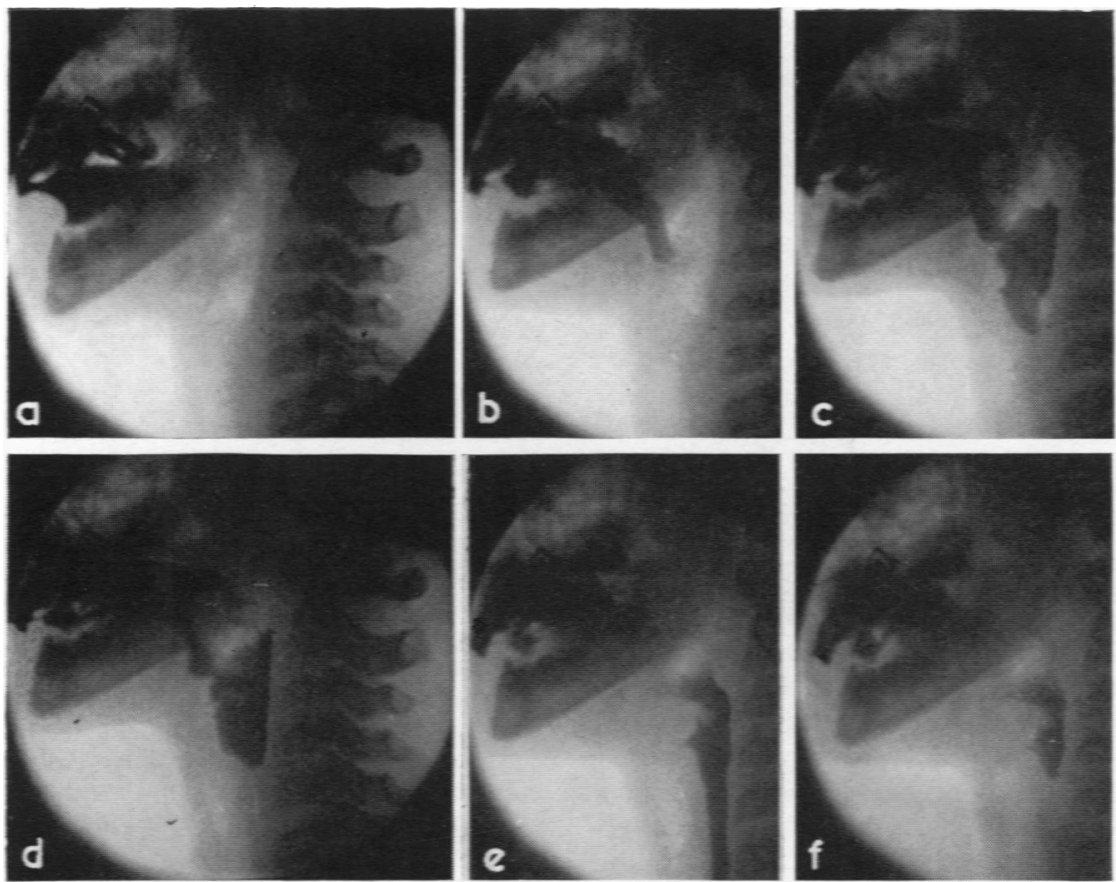

FIG. 1.-Series of prints from a lateral cineradiographic film of this child aged 8 years swallowing fluid barium suspension.

(a) Barium in the mouth. Barium was held in the mouth with the jaws apart and the lips sealed: the inner aspect of the lower lip which is between the incisor teeth is a prominent feature.

(b) Anterior portion of the floor of the mouth has elevated and the posterior portion of the tongue depressed. Barium flowing into the valleculae in front of the tonsils.

(c) The soft tissue mass of the tonsil can be seen indenting the barium from behind.

(d) The posterior portion of the tongue has elevated and the mouth is almost empty to the level of the anterior pillars of the fauces: small residue behind the incisor teeth.

(e) Main mass of the barium in the lower pharynx and oesophagus.

(f) A second or so later, after the first bolus has been swallowed, the child swallowed again. The barium in the lower pharynx is residue cleared from the mouth by the second swallow. There is still a small residue behind the incisor teeth.

Lateral Cineradiographic Films While Saying ' $T$ ' $(t)$. He appears to make this sound hy elevation of the tip of the tongue remnant and the floor of the mouth against the hard palate behind the incisor teeth.
Laterai Still Radiographs were obtained with the child Saying ' $E e^{\prime}$ (i) and ' $S$ ' $(s)$. Lateral radiography of the child (Figs. 3, 4a and b) while quietly breathing shows the mouth cavity to be filled with air, the floor of the mouth
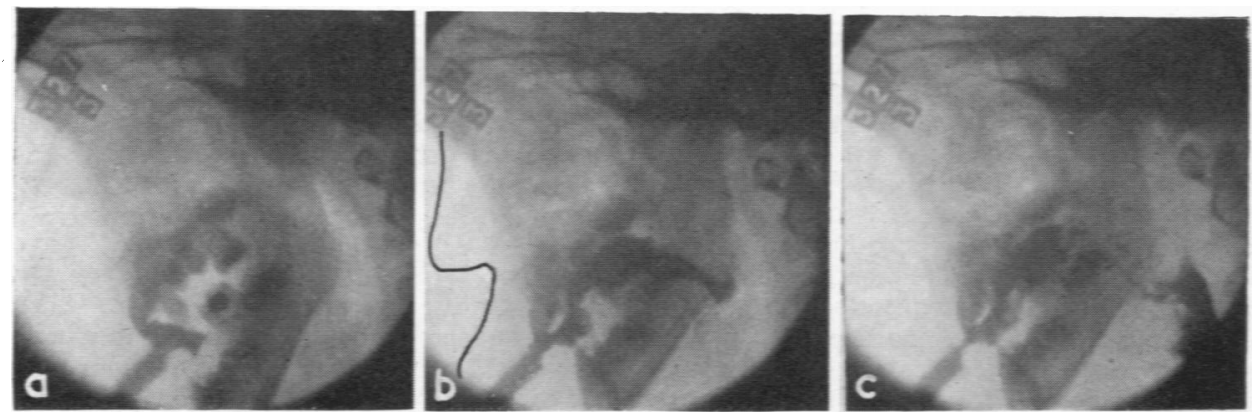

FIG. 2.- (a) This shows the child sucking barium suspension through a straw. The barium-filled straw can be seen in the bottom left-hand corner with some barium in the anterior portion of the mouth.

(b) Beginning of swallowing: the end of the straw is being occluded by the inner aspect of the lower lip. The heavy line indicates the skin margin of the protruding lips.

(c) The main mass of the barium is in the pharynx: there is considerable residue in the mouth; the end of the straw is practically occluded by lip tissue. 

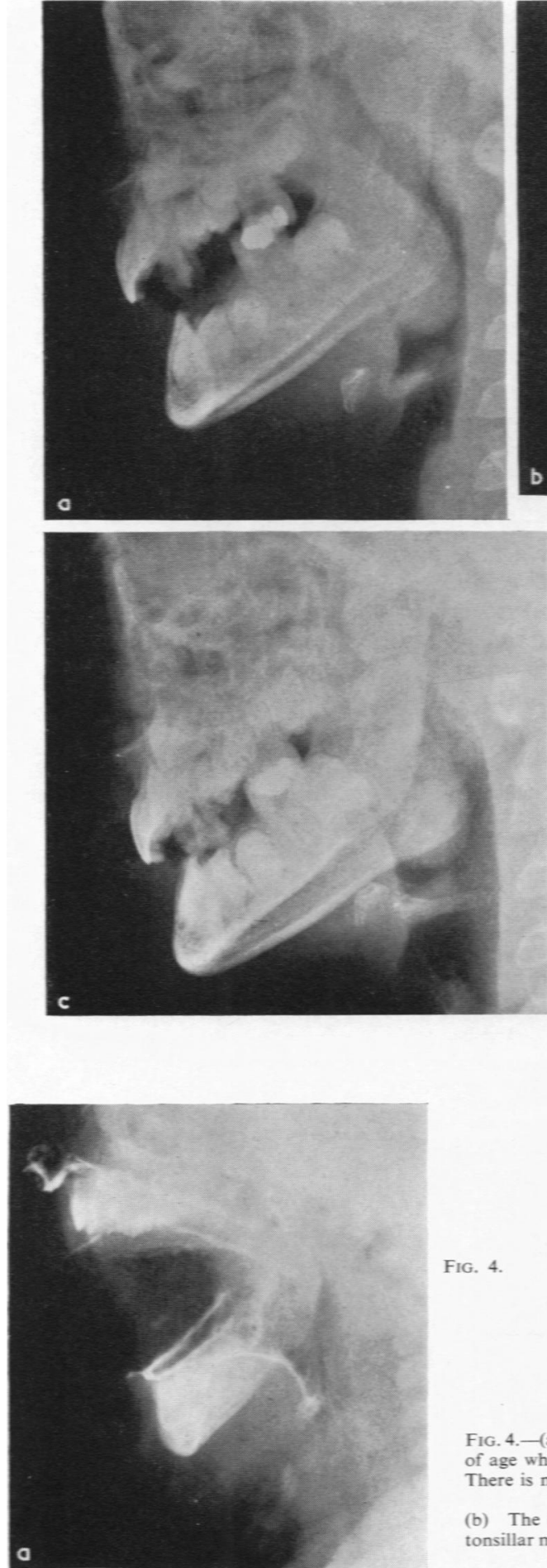

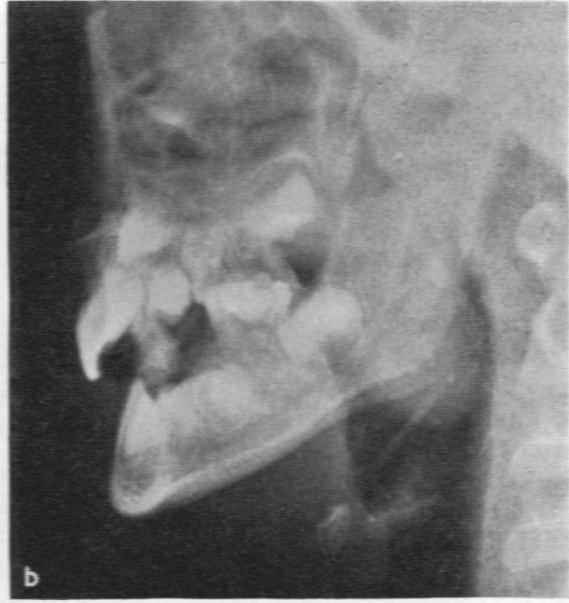

Fig. 3.

Fig. 3.- (a) Lateral radiograph of the child during quiet breathing. The lower incisor teeth can be seen posteriorly placed with reference to the upper incisor teeth and the soft tissue of the inner aspect of the lower lip fills the space between the teeth. The mass of the soft palate cannot be clearly distinguished from the large mass of the tonsils. The child has no difficulty with breathing.

(b) The child when phonating 'Ee' (i). The soft palate has elevated and is making contact with the adenoidal pad. The remnants of the tongue form an elevation in the mouth. The posterior portion of the tongue is more anteriorly placed than is normal and as a result the pharyngeal air space is bigger than normal. The calcified stylothyroid ligaments could be clearly seen.

(c) While phonating ' $\mathrm{S}$ ' (s); there is no evidence of the tongue reaching towards the incisor teeth.

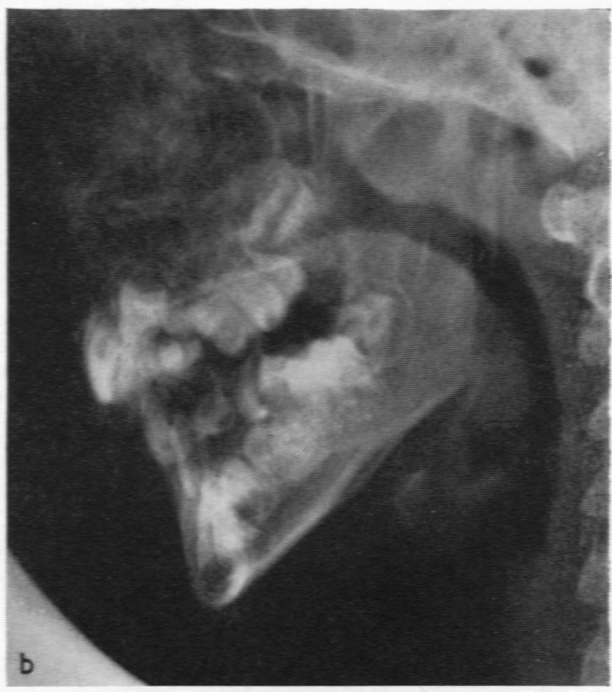

FIG, 4-(a) Lateral radiograph of the mouth of this child at 6 months of age while crying, barium coating the upper surface of the tongue. There is no evidence of the tongue above the lower alveolar margin, and the elevated tip usual in crying is absent.

(b) The child while breathing quietly at the age of $5 \frac{1}{2}$ years. The tonsillar masses are largely filling space between the posterior aspect of the tongue and the soft palate. 
merging imperceptibly into the tongue shadow posteriorly. There is no evidence of an anterior portion of tongue tissue filling the mouth as in the normal subject. The soft palate is in a mid position and its outline merges with the opacity due to the pair of moderately large tonsils. When phonating the sound 'Ee' (i) (Fig. 3b) the soft palate is raised and the levator eminence makes contact with the adenoidal pad at the level of or just above the arch of the atlas: this is normal. The posterior portion of the tongue is now separated from the tonsillar mass and makes a small elevation in the floor of the mouth in the region of the premolar teeth. This small elevation appears to be adequate for making a reasonable sounding 'Ee' (i). This film clearly shows that the stylo-hyoid ligament is calcified in two portions, which is unusual at this age: it was calcified at $5 \frac{1}{2}$ years. When making the sound ' $S$ ' (s) (Fig. 3c) the palate is elevated as in the previous figure, the bulge of the tongue being more posteriorly placed and merging with the anterior margin of the tonsillar shadow.

The adenoidal shadow in this child is within normal limits for his age; but the tonsillar shadows appear large.

\section{Discussion}

Our findings on both swallowing and speech confirm the findings of the previously reported cases, in that all of those cases to survive to childhood or early adult life are described as having good or fair swallowing and chewing. Only one patient, age 15 years, is described by de Jussieux in 1718 (Fitzwilliams, 1927) as having some difficulty. All those authors that commented on the speech have reported this as being good.

It is interesting to note that at 6 months of age when one looked into our child's mouth there was apparently no tongue at all as far as the fauces, and only on lateral radiography did we appreciate the fact that there was a portion of the posterior tongue present. Now, at the age of 8 years, this posterior portion of the tongue has tended to grow forward a little and has sufficient motility together with the very mobile floor of the mouth to make substitute movements that mimic a normal tongue fairly closely. For speech purposes, those actions usually performed with the tip of the tongue take place between the tongue and the hard palate and are made further back than is customary. It appears, therefore, that a child with this disability can be given a good prognosis as to swallowing and speech provided that his initial difficulties with sucking and feeding in the early weeks can be understood and overcome. The relatively normal speech has been achieved without speech therapy. He now has a brother of 2 years who is not entirely normal. He has a tongue thrust and interdental sigmatism with some deformity of the jaw.

Unless this child has repeated severe attacks of tonsillitis we consider it inadvisable to remove the tonsils or adenoids, since we think this might disorganize his speech and possibly his swallowing. We have previously suggested (Ardran, Kemp and Lind, 1958a and b) that one of the functions of the adenoids and possibly the tonsils is to act as soft tissue space fillers which normally atrophy at the time at which the infant's pharynx assumes adult proportions.

We are grateful to Dr. G. Dison, Medical Officer of Health and School Medical Officer for the Borough of Nuneaton, for his co-operation in our efforts to follow up this case.

\section{REFERENCES}

Ardran, G. M., Kemp, F. H. and Lind, J. (1958a). A cineradiographic study of bottle feeding. Brit. J. Radiol., 31, 11. - (1958b). A cineradiographic study of breast feeding. ibid., 31, 156.

Fitzwilliams, D. C. L. (1927). The Tongue and its Diseases. London.

Fulford, G. E., Ardran, G. M. and Kemp, F. H. (1956). Aglossia congenita: cineradiographic findings. Arch. Dis. Childh., 31, 400.

Pettersson. G. (1961). Aglossia congenita with bony fusion of the jaws: report of one case. Acta chir. scand., 122, 93. 